\title{
Synthesis and structural studies of a lanthanide complex of a calix[4]arene tris-amide
}

\author{
Mark I. Ogden ${ }^{\mathrm{a}^{*}}$, Brian W. Skelton ${ }^{\mathrm{b}}$ and Allan H. White ${ }^{\mathrm{b}}$ \\ ${ }^{a}$ Nanochemistry Research Institute, Curtin University of Technology, GPO Box U 1987, \\ Western Australia 6845, Australia, tel +6189266 2483, fax +618 9266 4699, e-mail \\ M.Ogden@curtin.edu.au \\ ${ }^{b}$ Chemistry, University of Western Australia, Crawley, Western Australia 6009
}

\begin{abstract}
The coordination chemistry of amide-substituted calixarenes is reviewed. The synthesis of a gadolinium complex of a tris-amide calix[4]arene is described, involving the reaction of 5,11,17,23-tetra-tert-butyl-24-hydroxy-26,27,28-tris(diethylcarbamoylmethoxy)calix[4]arene (L) with gadolinium picrate dodecahydrate. Structural studies demonstrated that the complex can be formulated as $[($ pic- $O) \mathrm{Gd}\{(\mathrm{L}-\mathrm{H})(\mathrm{EtOH})\}]($ pic $) \cdot 2 \mathrm{EtOH}$.
\end{abstract}

\section{Keywords}

Calixarene, lanthanide, picrate, crystal structure

\section{Résumé}

On fait une revue de chimie de coordination des calixarenes amide-substitué. Le synthese d'une complexe de gadolinium d'un tris-amide calix[4]arene est descrit; realisé par le rection de 5,11,17,23-tetra-tert-butyl-24-hydroxy-26,27,28tris(diethylcarbamoylmethoxy)calix[4]arene (L) avec gadolinium picrate dodecahydrate. Les études structurale á démontré que la complexe prend la forme : [(pic-O)Gd $\{(\mathrm{L}-$ $\mathrm{H})(\mathrm{EtOH})\}]$ (pic)•2EtOH

\section{Mots Clés}

Calixarene, lanthanide, picrate, structure crystalline 


\section{Introduction}

Amongst the wealth of functionalised calixarenes $[1,2]$ under investigation as selective receptors, the relatively simple derivatives produced by alkylation of the lower (phenolic) rim with O-donor functional groups continue to attract attention as useful ionophores [3]. In particular, amide moieties have been found to induce effective metal ion complexation, with structurally characterised examples available for alkali and alkaline earth metal ion complexes [4-12], as well as lanthanide [13-16] and transition metal [15,17-19] complexes. The majority of these structures involve a tetra- or bis- amide calix[4]arene in the cone conformer, most commonly with the diethyl amide substituent ( 1 and $\mathbf{2}$ respectively).

The coordination chemistry of the tetraamide calix[4]arene $\mathbf{1}$, is relatively well established, with larger metal cations interacting with the four amide and four ether oxygen atoms, to give an 8-coordinate geometry that is typically closer to a square antiprism than a cubic geometry. The potassium complex exhibits similar $\mathrm{K}-\mathrm{O}$ bond lengths for the amide and ether oxygens (2.74 and $2.70 \AA$ respectively) [4]. Smaller cations are found situated closer to the amide oxygens, as illustrated by the equivalent bond lengths in the sodium complex $(2.46$ and $2.54 \AA$ ) [4]. In the copper(II) complex of $\mathbf{1}$, the bond length difference is such that the copper atom is situated only $0.44 \AA$ from the least squares plane defined by the amide $\mathrm{O}$ atoms, with a mean bond length of $1.91 \AA$, and a presumably weak or negligible interaction with ether O atoms (mean distance $2.86 \AA$ ) [18]. The copper(II) complex of the pyrrolidinyl amide equivalent of $\mathbf{1}$ exhibits a similar metal-ligand interaction [17]. In addition to those mentioned above, complexes of this nature have been structurally characterised for $\mathrm{Sr}^{2+}[12]$, $\mathrm{Pb}^{2+}, \mathrm{Fe}^{2+}$ and $\mathrm{Zn}^{2+}[18]$. An exception is the complex of $\mathrm{Ni}^{2+}$, where the cation is approached by three amide $\mathrm{O}$ atoms (mean $\mathrm{Ni}-\mathrm{O}, 2.00 \AA$ ), and three ether $\mathrm{O}$ atoms (mean Ni-O, $2.23 \AA$ ), with the fourth ether $\mathrm{O}$ atom positioned $2.77 \AA$ from the $\mathrm{Ni}$ atom; the fourth amide moiety is oriented away from the cation so that the $\mathrm{Ni}$... O distance is $4.37 \AA$. The resulting capped 
octahedral geometry provides some indication that this ligand is more flexible than an analysis of the majority of known structures might suggest [18].

Substitution of the lower calixarene rim with a group of sufficient bulk is well known to lock the conformation of the calixarene [2], so that different conformers of 1 can be accessible; these include the partial cone (paco-1), and the 1,3-alternate (1,3-alt-1) and 1,2alternate conformations. A search of the Cambridge Structural Database revealed only two examples of metal complexes of these conformers. One is the $2: 1$ potassium complex of $1,3-$ alt-1, where the metal cations lie in the cavities defined by the four $\mathrm{O}$ atoms and 2 phenyl rings at each end of the tube-like conformation [5]. The second is the lanthanum(III) complex of paco-1, where the metal ion interacts directly with only two amide $\mathrm{O}$ atoms of the calixarene, the remainder of the coordination sphere comprising of three picrate anions, and two water molecules [14]. Further development of the coordination chemistry of tetraamide calix[4]arenes in conformations other than the cone will be required to make any detailed comparison of the coordination chemistry of the different conformers.

Complexes of the bisamide calixarene $\mathbf{2}$ have been structurally characterised for potassium, iron(III), and a number of lanthanide cations. The unsubstituted phenol moieties in 2 can be deprotonated so that complexes of the singly $(2-\mathrm{H})$ and doubly deprotonated $(2-2 \mathrm{H})$ ligand may be isolated, in addition to the neutral ligand adducts. These phenyl rings are also conformationally mobile, so that complexes of the cone, 1,3-alternate or partial cone conformers are accessible. A complex of $2-2 \mathrm{H}$ has been characterised with $\mathrm{Fe}^{3+}$; the $\mathrm{Fe}$ atom is bound to the six $\mathrm{O}$ atoms of the calixarene in a trigonal prismatic geometry, with average Fe-O bond distances: phenolic O, 1.82 ; amide-O, 2.04; ether-O atoms, $2.27 \AA$ [15], the calixarene assuming a cone conformation. When $\mathbf{2}$ is combined with lanthanide picrates in the presence of a base, complexes formulated as $[\operatorname{Ln}(2-2 \mathrm{H})($ pic $)]$ are isolated, where the ligand is again in a cone conformation with all six $\mathrm{O}$ atoms bound to the metal cation, with the Ln-O 
distances increasing in the same manner as the Fe complex. The coordination sphere is expanded to eight $\mathrm{O}$ atoms by bidentate coordination to the picrate anion, with the exception of $\mathrm{La}$, where the additional $\mathrm{O}$ atoms are derived from a unidentate picrate and water molecule [13].

Combination of $\mathbf{2}$ with lanthanide picrates in the absence of base (at least for $\mathrm{Ln}=\mathrm{La}$, $\mathrm{Ce}, \operatorname{Pr}$ and $\mathrm{Eu})$, results in the isolation of materials formulated as $\left[\operatorname{Ln} 2(\text { pic })_{3}\right]$. The Pr species has been structurally characterised [16]. The metal atom is nine-coordinate, bound to the two amide $\mathrm{O}$ atoms, one of the (protonated) phenol $\mathrm{O}$ atoms, and three bidentate picrate anions. Once again, the calixarene assumes the cone conformation. It is interesting to note that recrystallisation of these compounds from dichloromethane/methanol results in recovery of the starting material for $\mathrm{Ln}=\operatorname{Pr}$ and $\mathrm{Eu}$, but a new 10-coordinate complex for $\mathrm{Ln}=\mathrm{La}$ and Ce. The charge distribution in this complex is uncertain, but is probably best described as $\left[\operatorname{Ln}(2-2 \mathrm{H})(\mathrm{MeOH})_{2}(\right.$ pic $\left.)\right]$, with the ligand in the cone conformation [16].

To our knowledge, the only example of a metal complex of 2 with a conformation other than the cone, is the complex $[\mathrm{K} 2] \mathrm{I}_{3}$. Here the calixarene assumes the 1,3-alternate conformation in the solid-state, with the metal atom situated in the cavity defined by the four $\mathrm{O}$ atoms of the amide substituted phenyl rings and the two phenyl rings (as found in the dipotassium complex of 1,3-alt-1) [5]. ${ }^{5} \mathrm{NMR}$ spectroscopy indicates that the complex reverts to the cone conformation in solution. It is noteworthy that the potassium complex of the analogous $p$-phenylazocalix[4]arene bisamide assumes the cone conformation in the crystal, although here it appears that the ligand must be a monoanion [9]. The sodium complex of the methylated derivative, 2a, also exhibits the cone conformation [6].

An important aspect of calixarene chemistry is the availability of various macrocycle ring sizes. Analogous systems to those discussed above for the larger calixarenes are very poorly represented in terms of structural data; to our knowledge the only examples are the 1:1 
$\mathrm{Sr}^{2+}$ complex of the $p$-t-butylcalix[6]arene hexaamide, and two $2: 1 \mathrm{Sr}^{2+}$ complexes of the $p$ methoxy and $p$-t-butylcalix[8]arene octaamides [10]. Beyond the scope of the discussion here are related calixarene derivatives, such as thioamide-based ligands [17], and calixarenes functionalised with mixed donor groups [20-22]; it is noted that such systems are important in modifying the affinity of calixarenes for different cations.

Of particular relevance to the results presented in this paper are metal complexes of tris-substituted calix[4]arenes. A search of the Cambridge Structural Database for any trissubstituted calix[4]arene suggests that the only structurally characterised metal complex of such a ligand is the $\mathrm{Fe}^{3+}$ complex of $\mathbf{L}$ [19]. As part of our program to extend the structural chemistry of these calixarene derivatives, we describe below a lanthanide complex of $\mathbf{L}$, and draw comparisons with the previously published iron(III) complex.

\section{Experimental}

\subsection{Synthesis}

5,11,17,23-Tetra-tert-butyl-24-hydroxy-26,27,28-tris(diethylcarbamoylmethoxy)calix[4]arene [19] and gadolinium picrate dodecahydrate [23] were synthesised by literature methods. $[($ pic-O) $G d\{(L-H)(E t O H)\}]($ pic $) \cdot 2 E t O H .-\quad$ The calixarene $\mathbf{L}$ was dissolved in $1: 1$ dichloromethane-ethanol $(2 \mathrm{~mL})$. An approximately three-fold excess of $\mathrm{Gd}(\mathrm{pic})_{3} \cdot 12 \mathrm{H}_{2} \mathrm{O}$ was added, followed by one drop of triethylamine. Upon slow evaporation, the clear, orange solution deposited orange crystals suitable for single crystal X-ray diffraction studies.

The procedure was repeated without addition of triethylamine. Once again, orange crystals were deposited. Diffraction studies indicated that the two products were identical. IR $(\mathrm{KBr}$, $\left.\mathrm{cm}^{-1}\right), 1639,1616 v(\mathrm{C}=\mathrm{O}) ; 1574,1548 v_{\text {as }}\left(-\mathrm{NO}_{2}\right) ; 1364,1327 v_{\mathrm{s}}\left(-\mathrm{NO}_{2}\right)$. 


\subsection{Structure determination}

A full sphere of CCD area-detector diffractometer data was measured (Bruker AXS instrument; $\omega$-scans, $2 \theta_{\max }=58^{\circ}$; monochromatic $\mathrm{Mo} \mathrm{K \alpha}$ radiation, $\lambda=0.7107_{3} \AA, T$ ca. 153 $\mathrm{K})$ yielding 80070 reflections, these merging to 22022 unique $\left(R_{\text {int }}=0.067\right)$ after 'empirical'/multiscan absorption correction, 19145 with $F>4 \sigma(F)$ being considered 'observed' and used in the large block least squares refinement, refining anisotropic displacement parameter forms for the non-hydrogen atoms, $\left(x, y, z, U_{i s o}\right)_{\mathrm{H}}$ being included constrained at estimated values. Conventional residuals $R, R_{\mathrm{w}}$ on $|F|$ at convergence were $0.051,0.078$, reflection weights being $\left.\left(\sigma^{2}(F)+0.0003 F^{2}\right)^{-1}\right)$. t-butyl 34 was modelled as rotationally disordered over a pair of sites, occupancies refining to 0.691(6) and complement. Solvent residues were modelled as $\mathrm{EtOH}$, one lying within the calyx. Neutral atom complex scattering factors were employed within the Xtal 3.7 program system [24]. Pertinent results are given below and in the Tables and Figures, the latter showing 50\% probability displacement amplitude ellipsoids for the non-hydrogen atoms, hydrogen atoms having arbitrary radii of $0.1 \AA$. A full cif. deposition, including structure factor amplitudes, is also made (CCDC \#236949).

\subsection{Crystal/refinement data}

$[($ pic-O $) \mathrm{Gd}\{(\mathrm{L}-\mathrm{H})(\mathrm{EtOH})\}]($ pic $) \cdot 2 \mathrm{EtOH} \equiv \mathrm{C}_{80} \mathrm{H}_{110} \mathrm{GdN}_{9} \mathrm{O}_{24}, M=1739.1 . \quad$ Triclinic, space group $P \overline{1}\left(C_{i}^{1}\right.$, No. 2$), a=12.739(1), b=14.454(1), c=24.346(2) \AA, \alpha=101.757(2), \beta=$ 94.969(2), $\gamma=105.489(2)^{\circ}, V=4182 \AA^{3} . D_{c}=1.38_{1} \mathrm{~g} \mathrm{~cm}^{-3} . \mu_{\mathrm{Mo}}=8.7 \mathrm{~cm}^{-1}$; specimen: 0.70 x $0.15 \times 0.09 \mathrm{~mm} ;{ }^{\prime} T_{\min / \max }^{\prime}=0.66$. 


\section{Discussion}

The trisamide calixarene $\mathbf{L}$ dissolves readily in dichloromethane, combining with a solution of gadolinium picrate in ethanol to give an orange solution. Addition of triethylamine does not result in any observable change in the colour of the solution (in contrast to the observations made of the analogous reaction of the bisamide 2 , where addition of triethylamine induces a significant colour change consistent with deprotonation of the calixarene [16]). This simple observation suggests that the calixarene is deprotonated on addition of the metal ion alone, as was observed for the complexation of $\mathbf{L}$ with $\mathrm{Fe}^{3+}$. Single crystal diffraction studies indicated that the same crystalline product was isolated from the two reaction mixtures. It appears therefore, that coordination of a lanthanide cation induces deprotonation of the trisamide $\mathbf{L}$, more readily than for the bisamide $\mathbf{2}$.

The results of the 'low'-temperature single crystal structure determination are consistent, in terms of stoichiometries and connectivity, with the formulation of the complex as $[($ pic- $O) \mathrm{Gd}\{(\mathrm{L}-\mathrm{H})(\mathrm{EtOH})\}]($ pic $) \cdot 2 \mathrm{EtOH}$, i.e. a complex cation formed between the metal, a singly deprotonated anionic ligand (including an ethanol solvent), the deprotonated picrate ligand, an uncoordinated picrate counteranion and two lattice ethanol solvent molecules, the deprotonation of the coordinated phenolic groups consistent with the evidence of the 'straighter' associated Gd-O-C angles (Table I). The three amide pendants of the ligand each coordinate through their oxygen atoms forming, with the phenolate oxygens, five-membered chelate rings. The approach of the picrate is as a quasi-bidentate, one of the $O$-nitro oxygen atoms contacting at a distance appreciably longer than those in the remainder of the coordination sphere.

The cation forms an interesting contrast with its iron(III) counterpart [19], the latter devoid of the picrate; both species are shown in Fig. 1 in projection through the plane containing $\mathrm{O}(41)$ (nearest the viewer), $\mathrm{O}(21), \mathrm{M}$, the metal atoms being seven- $(\mathrm{M}=\mathrm{Fe}$; three 
chelates plus $\mathrm{O}(41))$ and eight(-(plus) - (Gd; three chelates plus $\mathrm{O}(41)$ plus picrate $\mathrm{O}(01)$ (plus nitro)) coordinate respectively, with the core geometries presented comparatively in Table I. The iron-containing cation is a good approximation to $m$-symmetry, the approximate mirror plane as defined about $(\mathrm{M}, \mathrm{O}(21,41))$ normal to the plane of the paper, and the symmetry conspicuously broken only by the pendants. Among the chelates, ring 2 is almost planar, the other pair slightly more divergent. The dihedral angle between chelate planes 1,3 is $3.27(6)^{\circ}$.

At first sight, the $M=G d$ complex cation appears similar, the larger metal atom enabling the approach of the picrate oxygen in such a manner as to offer the possibility of augmenting the array $\mathrm{O}(21,202,41)$ to the status of one of the pair of orthogonal planes of a dodecahedron, the other pair of chelates comprising the other plane. This outcome is curiously and interestingly foiled by a twist of chelate 1 brought about by a displacement of $\mathrm{O}(102)$, the largest divergences in the double entries of Table I concerning this atom; the chelate rings are now more decisively non-planar, with similar chiralities (Table II). In consequence of this perturbation, the picrate may approach in quasi-bidentate rather than unidentate mode. Whether a consequence of differences in repulsion parameters, or, more likely, the acidity of the metal, considerable differences are found in the relative strengths of binding of the two types of chelate oxygen donor for the two metals, the amide $\mathrm{O}(\mathrm{n} 02)$ more tightly bound in the iron(III) complex.

It is notable that the cavity defined by the phenyl rings in the Gd complex contains an ethanol molecule, whereas the cavity is unoccupied in the Fe complex. The conformation of the Fe complex is more "pinched" with rings 1 and 3 closer to parallel $\left(\mathrm{C}_{6}\right.$ dihedral angles, $\mathrm{Fe}$, 39.76(8); Gd, 46.4(1) $)$, and thus offers less space for a solvent molecule. It is tempting to suggest that metal ion binding might therefore be used to 'tune' the calixarene cavity as a receptor for organic guests, but further investigation will be required to determine if metal ion 
coordination is the dominant causative factor for conformational changes in these particular systems.

\section{References}

[1] Z. Asfari, V. Böhmer, J. Harrowfield, J. Vicens (Eds), Calixarenes 2001, Kluwer Academic Publishers, Dordrecht, Boston, London, 2001.

[2] C. D. Gutsche, Calixarenes Revisited, Monographs in Supramolecular Chemistry, No. 1, J. F. Stoddart (Ed.), The Royal Society of Chemistry, Cambridge, 1998.

[3] F. Arnaud-Neu, M. A. McKervey, M.-J. Schwing-Weill, in reference [1], p. 385.

[4] A. Arduini, G. Giorgi, A. Pochini, A. Secchi, F. Ugozzoli, Tetrahedron 57 (2001) 2411.

[5] P. D. Beer, M. G. B. Drew, P. A. Gale, P. B. Leeson, M. I. Ogden, J. Chem. Soc., Dalton Trans. (1994) 3479.

[6] N. J. Wolf, E. M. Georgiev, A. T. Yordanov, B. R. Whittlesey, H. F. Koch, D. M. Roundhill, Polyhedron, 18 (1999) 885.

[7] A. Moser, G. P. A. Yap, C. Detellier, J. Chem. Soc., Dalton Trans. (2002) 428.

[8] M. Bochenska, A. Zielinska, V. C. Kravtsov, M. Gdaniec, E. Luks, W. RadeckaParyzek, Polyhedron 21 (2002) 763.

[9] H. Halouani, I. Dumazet-Bonnamour, C. Duchamp, C. Bavoux, N. Ehlinger, M. Perrin, R. Lamartine, Eur. J. Org. Chem. (2002) 4202.

[10] A. Casnati, L. Baldini, N. Pelizzi, K. Rissanen, F. Ugozzoli, R. Ungaro, J. Chem. Soc., Dalton Trans. (2000) 3411.

[11] A. Casnati, S. Barboso, H. Rouquette, M. J. Schwing-Weill, F. Arnaud-Neu, J. F. Dozol, R. Ungaro, J. Am. Chem. Soc. 123 (2001) 12182.

[12] N. Muzet, G. Wipff, A. Casnati, L. Domiano, R. Ungaro, F. Ugozzoli, J. Chem. Soc., Perkin Trans. 2 (1996) 1065.

[13] P. D. Beer, M. G. B. Drew, M. Kan, P. B. Leeson, M. I. Ogden, G. Williams, Inorg. Chem. 35 (1996) 2202.

[14] P. D. Beer, M. G. B. Drew, M. I. Ogden, J. Chem. Soc., Dalton Trans. (1997) 1489.

[15] P. D. Beer, M. G. B. Drew, P. B. Leeson, M. I. Ogden, Inorg. Chim. Acta 246 (1996) 133.

[16] P. D. Beer, M. G. B. Drew, A. Grieve, M. I. Ogden, J. Chem. Soc., Dalton Trans. (1995) 3455. 
[17] F. Arnaud-Neu, G. Barrett, D. Corry, S. Cremin, G. Ferguson, J. F. Gallagher, S. J. Harris, M. A. McKervey, M. J. Schwing-Weill, J. Chem. Soc., Perkin Trans. 2 (1997) 575.

[18] P. D. Beer, M. G. B. Drew, P. B. Leeson, M. I. Ogden, J. Chem. Soc., Dalton Trans., (1995) 1273.

[19] M. I. Ogden, B. W. Skelton, A. H. White, J. Chem. Soc., Dalton Trans. (2001) 3073.

[20] P. D. Beer, G. D. Brindley, O. D. Fox, A. Grieve, M. I. Ogden, F. Szemes, M. G. B. Drew, J. Chem. Soc., Dalton Trans. (2002) 3101.

[21] C. Wieser, D. Matt, J. Fischer, A. Harriman, J. Chem. Soc., Dalton Trans. (1997) 2391.

[22] M. Baaden, G. Wipff, M. R. Yaftian, M. Burgard, D. Matt, J. Chem. Soc., Perkin Trans. 2 (2000) 1315.

[23] J. M. Harrowfield, W. M. Lu, B. W. Skelton, A. H. White, Aust. J. Chem., 47 (1994) 321.

[24] S. R. Hall, D. J. du Boulay, R. Olthof-Hazekamp (eds.), The Xtal 3.7 System, University of Western Australia, 2001. 
Table I. The gadolinium environment in the cation

$r \AA$ are the Gd-O distances; other entries in the matrix are the angles subtended at the gadolinium by the relevant oxygen atoms at the head of the row and column. Counterpart values for the Fe complex are given italicised below those of the Gd complex.

\begin{tabular}{|c|c|c|c|c|c|c|c|c|c|}
\hline Atom & $r$ & $\mathrm{O}(102)$ & $\mathrm{O}(21)$ & $\mathrm{O}(202)$ & $\mathrm{O}(31)$ & $\mathrm{O}(302)$ & $\mathrm{O}(41)$ & $\mathrm{O}(01)$ & $\mathrm{O}(021)$ \\
\hline $\mathrm{O}(11)$ & $2.510(3)$ & $62.36(9)$ & $76.37(8)$ & $125.84(9)$ & $129.42(7)$ & $153.16(9)$ & 75.02(9) & $76.58(9)$ & $116.01(8)$ \\
\hline$(\delta r 0.21)$ & $2.300(2)$ & $71.06(6)$ & $74.79(5)$ & $92.40(7)$ & $138.91(6)$ & $150.57(6)$ & $84.09(6)$ & & \\
\hline $\mathrm{O}(102)$ & $2.414(3)$ & & $73.34(8)$ & $73.13(9)$ & $138.49(9)$ & $128.0(1)$ & $137.2(1)$ & $79.31(9)$ & $63.4(1)$ \\
\hline$(\delta r 0.35)$ & $2.064(2)$ & & $133.49(6)$ & $82.82(7)$ & $149.21(6)$ & $79.51(7)$ & $98.03(7)$ & & \\
\hline $\mathrm{O}(21)$ & $2.618(2)$ & & & $62.02(9)$ & $72.71(7)$ & $128.80(8)$ & $100.90(9)$ & $148.10(8)$ & $116.56(9)$ \\
\hline$(\delta r 0.12)$ & $2.495(2)$ & & & $67.93(7)$ & $73.60(5)$ & $129.34(6)$ & $108.93(7)$ & & \\
\hline $\mathrm{O}(202)$ & $2.369(2)$ & & & & $70.22(8)$ & $79.6(1)$ & $142.48(8)$ & $124.70(9)$ & $62.44(9)$ \\
\hline$(\delta r 0.37)$ & $1.999(2)$ & & & & $99.33(7)$ & $84.19(8)$ & $175.88(8)$ & & \\
\hline $\mathrm{O}(31)$ & $2.576(2)$ & & & & & $62.72(8)$ & $72.81(9)$ & $138.77(9)$ & $113.38(9)$ \\
\hline$(\delta r 0.21)$ & $2.365(2)$ & & & & & $70.24(6)$ & $82.02(6)$ & & \\
\hline $\mathrm{O}(302)$ & $2.398(2)$ & & & & & & $89.3(1)$ & $81.35(9)$ & $64.86(9)$ \\
\hline$(\delta r 0.35)$ & $2.045(2)$ & & & & & & 99.93(7) & & \\
\hline $\mathrm{O}(41)$ & $2.132(3)$ & & & & & & & $88.1(1)$ & $142.3(1)$ \\
\hline$(\delta r 0.34)$ & $1.792(2)$ & & & & & & & & \\
\hline $\mathrm{O}(01)$ & $2.371(2)$ & & & & & & & & $62.4(1)$ \\
\hline $\mathrm{O}(021)$ & $2.799(4)$ & & & & & & & & \\
\hline
\end{tabular}

$\mathrm{Gd}(\mathrm{Fe})-\mathrm{O}(\mathrm{n} 1)-\mathrm{C}(\mathrm{n} 1)(\mathrm{n}=1,4)$ are: 111.8(3) (125.4(1)), 136.5(2) (138.6(1)), 131.9(2) (125.5(1)), 163.1(2) (164.2(2) $)^{\circ}$; $\mathrm{Gd}(\mathrm{Fe})$ lies $1.490(8)(1.823(4)), 1.575(8)(1.551(5)), 1.549(7)(1.729(4)), 0.537(7)(0.400(5)) \AA$ out of the associated $\mathrm{C}_{6}$ planes C(n1-n6). $\mathrm{Gd}(\mathrm{Fe})-\mathrm{O}(\mathrm{n} 02)-\mathrm{C}(\mathrm{n} 02)(\mathrm{n}=1,3)$ are: 119.2(3) (122.8(2)), 121.3(3) (132.4(2)), 123.9(2) (127.4(2)); $\mathrm{Gd}(\mathrm{Fe})$ lies 1.265(6) (0.622(4)), 1.319(6) (0.169(5)), 0.564(6) (0.168(4)) $\AA$ out of the amide planes $\mathrm{C}(\mathrm{n} 01, \mathrm{n} 02)$, $\mathrm{O}(\mathrm{n} 02), \mathrm{N}(\mathrm{n} 0)(\mathrm{n}=1-3)$. In the picrate, nitro group planes $\mathrm{CNO}_{2}(2,4,6)$ make dihedral angles of 21.2(2), 1.1(2), 32.2(2) with the coordinated picrate $\mathrm{C}_{6}$ plane and $2^{\prime}, 4^{\prime}, 6^{\prime} 29.8(3), 5.7(3), 37.3(3)^{\circ}$ with the uncoordinated. $\mathrm{Gd}-\mathrm{O}(01)$ $\mathrm{C}(01)$ is $144.4(3)^{\circ}$. The dihedral angles between the amide C.CO.N planes with their parent $\mathrm{C}_{6}$ planes are $(\mathrm{n}=1-3)$ : $85.5(2)(84.74(9)), 81.4(1)(87.4(1)), 84.2(1)(85.1(1))^{\circ}$. Dihedral angles between the calix $\mathrm{C}_{6}$ planes are $(1 / 2,3,4)$ : 
80.4(1) (80.01(8)), 46.4(1) (39.76(8), 72.5(1) (77.61(8); (2/3, 4) 82.7(1) (81.28(8)), 76.9(1) (83.87(8)); (3/4) 69.8(1) $(69.89(8))^{\circ}$. 
Table II. Chelate ring torsion angles (degrees)

Values for $\mathrm{M}=\mathrm{Fe}$ are given italicised below those for $\mathrm{M}=\mathrm{Gd}^{19}$

\begin{tabular}{lrrr}
\hline Angle $\backslash \mathrm{n}$ & 1 & \multicolumn{1}{c}{2} & \multicolumn{1}{c}{3} \\
\hline $\mathrm{M}-\mathrm{O}(\mathrm{n} 1)-\mathrm{C}(\mathrm{n} 01)-\mathrm{C}(\mathrm{n} 02)$ & $24.4(3)$ & $21.7(3)$ & $34.3(4)$ \\
& $15.6(2)$ & $4.2(2)$ & $-12.9(2)$ \\
$\mathrm{O}(\mathrm{n} 1)-\mathrm{C}(\mathrm{n} 01)-\mathrm{C}(\mathrm{n} 02)-\mathrm{O}(\mathrm{n} 01)$ & $6.5(5)$ & $8.2(4)$ & $-13.5(5)$ \\
& $1.7(3)$ & $-0.4(3)$ & $5.9(3)$ \\
$\mathrm{C}(\mathrm{n} 01)-\mathrm{C}(\mathrm{n} 02)-\mathrm{O}(\mathrm{n} 02)-\mathrm{M}$ & $-36.9(4)$ & $-40.3(3)$ & $-17.6(5)$ \\
& $-21.9(3)$ & $-5.7(4)$ & $6.1(3)$ \\
$\mathrm{C}(\mathrm{n} 02)-\mathrm{O}(\mathrm{n} 02)-\mathrm{M}-\mathrm{O}(\mathrm{n} 1)$ & $35.3(3)$ & $36.9(2)$ & $26.4(3)$ \\
& $22.7(2)$ & $6.1(2)$ & $-10.2(2)$ \\
$\mathrm{O}(\mathrm{n} 02)-\mathrm{M}-\mathrm{O}(\mathrm{n} 1)-\mathrm{C}(\mathrm{n} 01)$ & $-30.3(2)$ & $-28.9(2)$ & $-31.5(2)$ \\
& $-19.8(1)$ & $-5.1(1)$ & $12.4(2)$
\end{tabular}

The chiralities of the values for the iron compound are presented as the inverses of those previously recorded to assist comparison. 
Structures
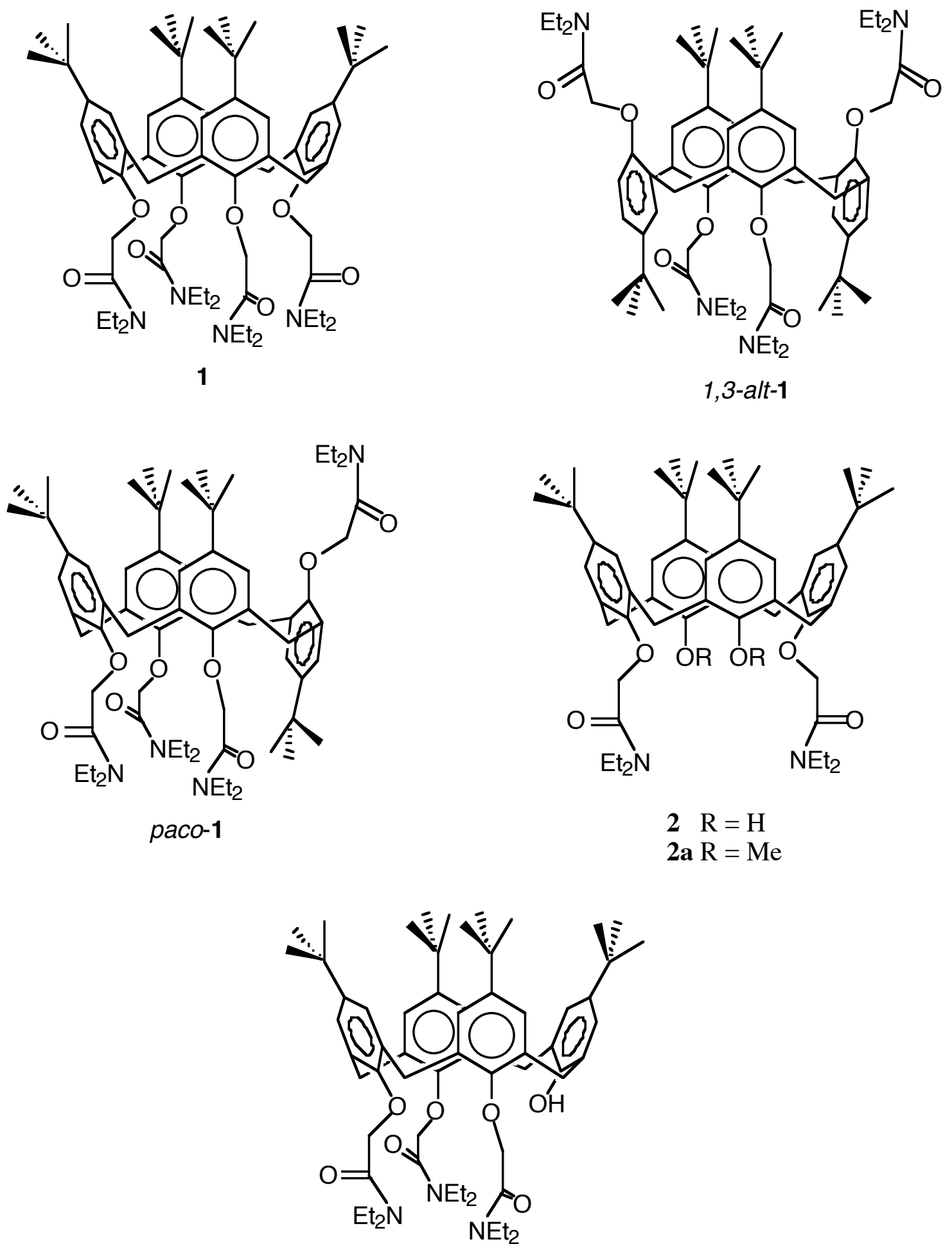

$\mathbf{L}$ 


\section{Figure caption}

Fig. 1 Projections of (a) the $[\mathrm{Fe}(\mathrm{L}-\mathrm{H})]^{2+}$ and (b) the $[(\text { pic }) \mathrm{Gd}\{(\mathrm{L}-\mathrm{H})(\mathrm{EtOH})\}]^{+}$cations. 
Fig 1(a)

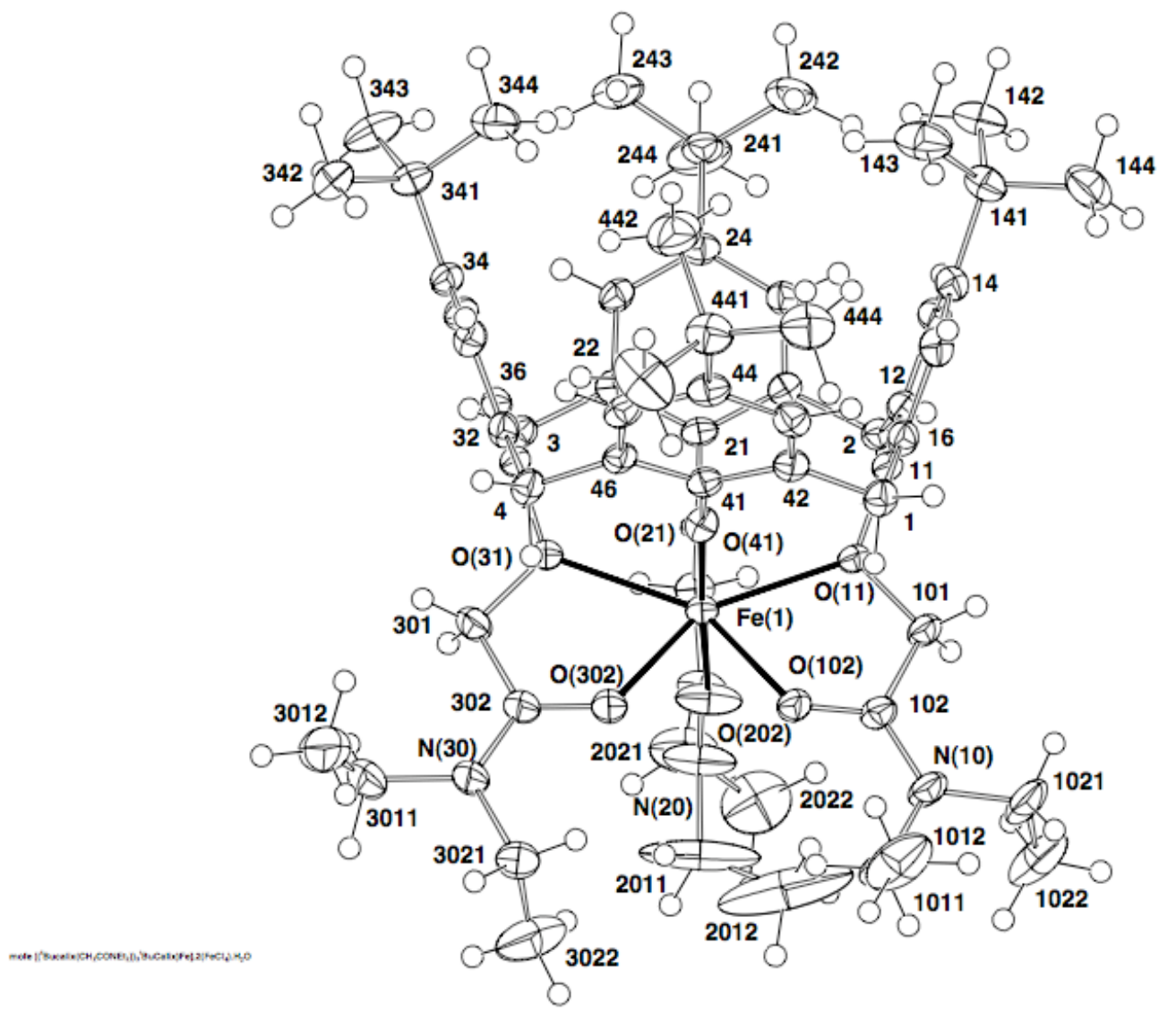


Fig 1(b)

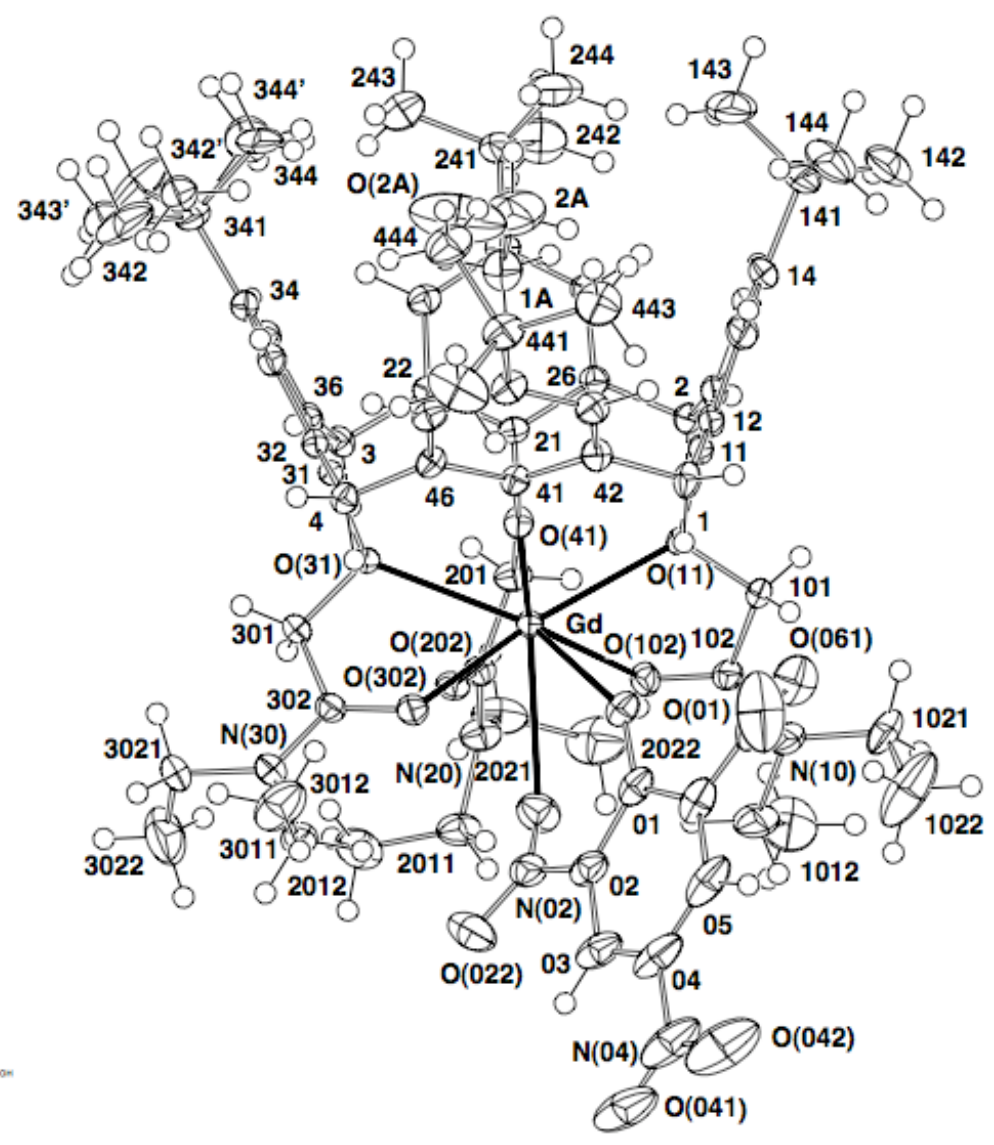

